\title{
MACHINE REPAIR PROBLEM IN PRODUCTION SYSTEMS WITH SPARES AND SERVER VACATIONS
}

\author{
Jau-Chuan Ke ${ }^{1}$, Ssu-Lang LeE ${ }^{2}$ and Cheng-Hwai Liou ${ }^{2}$
}

\begin{abstract}
This paper studies the machine repair problem consisting of $M$ operating machines with $S$ spare machines, and $R$ servers (repairmen) who leave for a vacation of random length when there are no failed machines queuing up for repair in the repair facility. At the end of the vacation the servers return to the repair facility and operate one of three vacation policies: single vacation, multiple vacation, and hybrid single/multiple vacation. The Markov process and the matrixgeometric approach are used to develop the steady-state probabilities of the number of failed machines in the system as well as the performance measures. A cost model is developed to obtain the optimal values of the number of spares and the number of servers while maintaining a minimum specified level of system availability. Some numerical experiments are performed and some conclusions are drawn.
\end{abstract}

Keywords. Hybrid multiple/single vacation, machine repair problem, matrix-geometric approach, multiple vacations, single vacation.

Mathematics Subject Classification. 60K25, 90B22.

\section{INTRODUCTION}

We consider a machine repair problem where a group of $M$ operating machines is under the supervision of one or more repairmen (servers) in the repair facility. If at any time a machine fails, it is sent to the repair facility for repair. This incidence may lead to loss of production because the failed machine must stay in the repair

Received May 3, 2007. Accepted September 4, 2008.

1 Department of Applied Statistics, National Taichung Institute of Technology, No. 129, Sec. 3, Sanmin Rd., Taichung 404, Taiwan, R.O.C.; jauchuan@ntit.edu.tw

2 Department of Accounting, National Taichung Institute of Technology, Taichung 404,

Taiwan, R.O.C. 
facility for some time. To avoid any loss of production, the plant always keeps some spare machines, say $S$, so that a spare machine can immediately act as a substitute when an operating machine fails. Meanwhile, the repairmen leave for a vacation of random length whenever there are no failed machines queuing up for repair in the repair facility. If the repairmen find at the repair facility any failed machines in the queue when they return from a vacation, they immediately repair the failed machines until there are no failed machines on the waiting list. A real-world example of this vacation model can be realized in the manufacturing/productionassembly system where the servers in their idle time may be assigned to perform some extra operations such as additional work, preventive maintenance.

In a classical machine repair model, it is assumed that the servers remain idle until the next machine fails. Numerous machine repair problems have been proposed, for example, no-spare M/M/R model by Feller [1], cold-standby M/M/R model by Toft and Boothroyd [2], and warm-standby M/M/R model by Sivazlian and Wang [3]. The $\mathrm{M} / \mathrm{M} / \mathrm{R}$ machine repair problem with mixed-standby spare was investigated by Wang [4]. Wang and Lee [5] generalized Sivazlian and Wang's model [3] to the $\mathrm{M} / \mathrm{M} / \mathrm{R}$ machine repair problem with cold-standby and multiple modes of failure. Recently, Jain et al. [6] examined the reliability characteristics of a $\mathrm{M} / \mathrm{M} / 1$ machine repair model with $\mathrm{M}$ operating and $\mathrm{S}$ warm spares, where the failed machines may renege when the server is busy. Cost (profit) models in the machine repair problem have been investigated by several authors including Ashcroft [7], Elsayed [8], Hilliard [9], Gross et al. [10,11], Sivazlian and Wang [3], and Wang $[4,5]$. Recently, Wang et al. [12] examined the profit analysis of the $\mathrm{M} / \mathrm{M} / \mathrm{R} /$ machine repair problem with balking reneging, and standby switch failures. In [12], the direct search and Quasi-Newton methods were used to calculated optimum values of two discrete variables and two continuous variables, respectively. As for a vacation model, comprehensive and excellent surveys, including some applications, were proposed by Doshi [13] and Takagi [14]. Gupta [15] first analysed the $\mathrm{M} / \mathrm{M} / 1$ machine repair problem with warm spares and server vacations. He gave an algorithm to compute the steady-state probability distribution of the number of failed machines in the system, but no cost analysis was provided. Recently, Jain et al. [16] studied bi-level switch-over policy of M/M/2 machine repair model with spares, where one of two servers performs setup before providing services, and performs vacations when no failed machines are queued for services. Ke [17] studied the M/M/1 machine interference problem with an un-reliable server and state-dependent service rate under single/multiple vacation policy. Comparable work on machine repair models with multi-server involving multiple vacations and single vacation is rarely found in the literature. This motivates us to develop the $M / M / R$ machine repair problem with spares where the servers are characterized by three vacation policies: multiple vacations, single vacation, and hybrid single/multiple vacation.

The purpose of this paper is threefold. The first is to develop steady-state solutions for $M / M / R$ machine repair problems with spares and server vacations. These solutions are used to obtain the various system performance measures, such as the expected number of failed machines, the expected number of idle and busy 
servers, machine availability, operative utilization, etc. The second is to develop a cost model for these three policies to determine the joint optimum number of spares and servers in order to minimize the steady-state expected cost per unit time, while maintaining a specified level of system availability. The third is to perform a sensitivity analysis to investigate the effect on the joint optimum number of spares and servers if the system parameters take on some specific values. A numerical comparison of the different vacation policies based on the minimum expected cost also is provided.

\section{MODEL DESCRIPTION}

We consider a machine repair model with $L$ identical and independent machines that are subject to breakdowns, and $R$ servers who are responsible for maintaining these machines. As many as $M$ machines can be operated simultaneously in parallel; the rest of the $S=L-M$ machines are available as spares. Spares are considered to be either cold-standby, warm-standby or hot-standby. A standby unit is called "cold standby" if its failure rate is zero. The standby unit is referred to as "warm standby" when the failure rate is not zero and is less than the failure rate of an operating unit, and the standby is referred to as "hot standby" when the failure rate is the same as an operating unit. If all spares are being used and a breakdown occurs, we say that the system becomes short. In this case there are less than $M$ operating machines.

\subsection{Assumptions}

When each server finds at the repair facility no failed machines queuing up for repair, he leaves the repair facility for a vacation of random length. Upon returning from the first vacation in an idle period, each server inspects the repair facility and decides whether to take another vacation, to remain idle at the repair facility, or to resume repairing the waiting failed machines. One of the following three vacation policies are considered;

Policy 1 - single vacation: If there is an empty queue in the repair facility, he waits idly for the first failed machine to arrive, upon which he starts repairing the failed machines. On the other hand, if there is not an empty queue, he immediately starts to repair the waiting failed machines.

Policy 2 - multiple vacations: If there is not an empty queue in the repair facility, the server starts to repair the waiting failed machines. Otherwise, if there is an empty queue in the repair facility, the server leaves immediately for another vacation.

Policy 3 - hybrid single/multiple vacations: If there is an empty queue in the repair facility, he waits for a random duration and then takes another vacation (see [18]). 
Furthermore, our analysis is based on the following assumptions.

1. Operating machines are subject to breakdowns according to an independent Poisson distribution with rate $\lambda$. When an operating machine breaks down, it will immediately be backed up by an available spare.

2. Each of the available spare machines fails independently of the state of all the others with Poisson rate $\alpha$, where $0 \leq \alpha \leq \lambda$. When a spare machine moves into an operating state, its characteristics will be that of an operating machine.

3. Whenever a machine fails, it is immediately sent to the repair facility where repair work is provided in the order of breakdowns, with an identical repair rate $\mu$. The repair time distribution is assumed to be exponentially distributed.

4. Each server can repair only one failed machine at a time. The failed machine which on arriving at the repair facility finds it busy or on a vacation must wait in the queue until a server is available.

5. When a failed operating machine or a failed spare machine is repaired, it is as good as a new one and goes into standby state unless the system is short and the repaired machine is immediately sent back to an operating state.

6. All vacations of servers are independent and identically distributed as an exponential distribution with rate $\theta(\gamma)$. Parameter $\theta(\gamma)$ represents the rate at which the server returns from vacation and finds the number of failed machines is more (less) than the number of the available servers in the facility.

7. Under the hybrid single/multiple vacation policy, the server waits for an exponential random duration with parameter $\epsilon$ if still no machine breaks down, and then takes another vacation.

8. The various stochastic processes involved in the system are independent of each other.

It should be noted that the machine repair model with vacations can have single vacation $(\gamma=\theta, \epsilon=0)$, multiple vacations $(\gamma=\epsilon=0)$ or hybrid single $/$ multiple vacations $(\gamma=\theta, \epsilon \neq 0)$. Parameters $\epsilon$ and $\gamma$ are introduced in order to analyze a generalized model to accommodate single vacation, multiple vacation or hybrid single/multiple vacation models.

\subsection{Practical justification of our model}

A number of practical problems arise which may be formulated as one in which the performance measures of a system are often improved by the provision of spare machines or parallel redundant machines with facilities to repair the failed one. One particular problem where this model is applied is in the study of a production line system. Consider a manufacturing plant has a pool of $L$ homogeneous machines, up to $M$ of which produce certain items in the production mode. The good quality items are marketed and sold while the defective ones are kept in the storage and are reworked by the rest $S(S=L-M)$ machines in the repair mode. These $L$ machines are unreliable. When those machines are broken unpredictably, they will be repaired by $R$ mechanics in the repair division. To keep the production capacity, the remaining $S$ machines may convert from repair mode to production mode in case the $M$ machines in production line are out of order. 
After the broken machines are repaired, those machines are converted to repair mode to rework the defective items. When a broken machine is repaired, it is switched to repair mode unless the system is shut down and the repaired machine is immediately sent back to production mode. When there is no machine needed to be repaired, the $R$ repairmen may conduct other secondary tasks, for example, attending a training course, or inspecting machines or products. The secondary tasks would correspond to the vacation of mechanics.

Another practical problem based on the work of Chelst et al. [19], we assume an unloader system where trains arrive which bring coal from various mines. In this system, there are $(M+S)$ identical trains involved in the coal transportation, where $M$ trains must be arranged to bring coal from various mines, $S$ trains are in prearrangement (spare trains), and there are $R$ coal unloaders. An unloaded train goes to the coal fields and return with a trainload of coal. A train that is arranged to bring coal from the mines to the unloader system to dump the coal is backed up by a spare train, if any is available. One coal unloader can handle only one train at a time. When no unloaded train is unloaded, the coal unloader may be utilized for other purposes, for example, the task of maintenance or clean. These coal unloaders correspond to servers and the unloaded times are as service times.

\subsection{SPECial CASES}

Case 1. The $\mathrm{M} / \mathrm{M} / \mathrm{R}$ machine repair problem with warm spares considered by Sivazlian and Wang [3] is a special case of our model with $\epsilon=0, \gamma=0$ and $\theta=0$.

Case 2. If $R=1$, our model becomes the $\mathrm{M} / \mathrm{M} / 1$ machine repair problem with spares and server vacations considered by Gupta [15].

Case 3. The corresponding result for the ordinary $\mathrm{M} / \mathrm{M} / \mathrm{R} / \mathrm{L}$ queueing system (see Gross and Harris [20]) can be found by setting $\epsilon=0, \gamma=0, \theta=0$, $\alpha=0$ and $S=L-1$.

Case 4. The new result for the ordinary $\mathrm{M} / \mathrm{M} / \mathrm{R} / \mathrm{L}$ queueing system with server single vacation (multiple vacation) can only be obtained by setting $\epsilon=0$, $\gamma=\theta(\gamma=0), \alpha=0$ and $S=L-1$.

Case 5. The new result for the ordinary $\mathrm{M} / \mathrm{M} / \mathrm{R} / \mathrm{L}$ queueing system with server hybrid single/multiple vacation can only be obtained by setting $\gamma=\theta$, $\alpha=0$ and $S=L-1$.

Case 6. The new result for the ordinary $\mathrm{M} / \mathrm{M} / \mathrm{R} / \infty$ queueing system with server single vacation (multiple vacation) can only be obtained by setting $\epsilon=0$, $\gamma=\theta(\gamma=0), \alpha=0, S=L-1$ and $L \rightarrow \infty$.

Case \%. The new result for the ordinary $\mathrm{M} / \mathrm{M} / \mathrm{R} / \infty$ queueing system with server hybrid single/multiple vacation can only be obtained by setting $\gamma=\theta$, $\alpha=0, S=L-1$ and $L \rightarrow \infty$. 


\section{Steady-State Results}

For the $\mathrm{M} / \mathrm{M} / \mathrm{R}$ machine repair model with spares and server vacations we describe the state of the system by the pairs $\{(i, n): i=0,1, \ldots, R$, and $0 \leq n \leq$ $M+S=L\}$, where $i$ and $n$ are denoting the number of available (idle or busy) servers and the number of failed machines in the system, respectively.

The mean failure rate $\lambda_{n}$ and mean repair rate $\mu_{n}$ for this system are given by

$$
\lambda_{n}=\left\{\begin{array}{cl}
M \lambda+(S-n) \alpha, & n=0,1,2, \ldots, \mathrm{S} ; \\
(L-n) \lambda, & n=\mathrm{S}+1, \mathrm{~S}+2, \mathrm{~S}+3, \ldots, \mathrm{M}+\mathrm{S}=\mathrm{L} ; \\
0, & \text { otherwise },
\end{array}\right.
$$

and

$$
\mu_{n}=\left\{\begin{array}{cl}
i \mu, & n=\mathrm{i}, \mathrm{i}+1, \mathrm{i}+2, \ldots, \mathrm{M}+\mathrm{S}=\mathrm{L} \\
0, & \text { otherwise }
\end{array}\right.
$$

In steady-state, the following notations are used.

$P_{0, n} \equiv$ probability that there are $n$ failed machines in the system when all the servers take vacations;

$P_{i, n} \equiv$ probability that there are $n$ failed machines in the system when there are $i$ servers working;

where $i=1,2, \ldots, R$, and $0 \leq n \leq L$.

Referring to the state-transition-rate diagram for the $M / M / R$ machine repair problem with spares and server multiple vacations shown in Figure 1, we easily obtain the governing system steady-state equations. Following the concepts by Neuts [21] while studying the embedded Markov chains of many practical queues, a matrix-geometric approach is used to analyze the the $\mathrm{M} / \mathrm{M} / \mathrm{R}$ machine repair system and the closed-form expressions for the steady-state probabilities $P_{i, n}(0 \leq$ $i \leq R$ and $0 \leq n \leq L)$ are further developed. One finds that the transition rate matrix $Q$ of this Markov chain has the block-tridiagonal form:

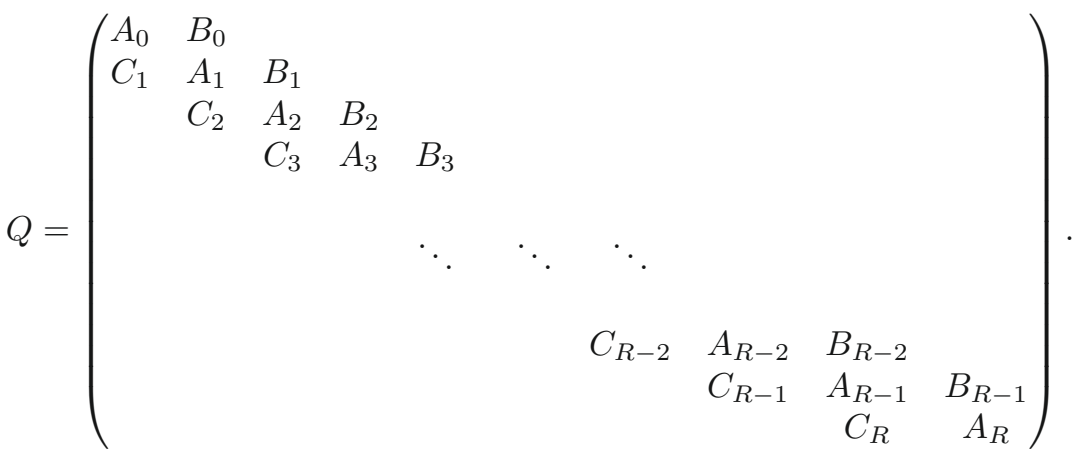




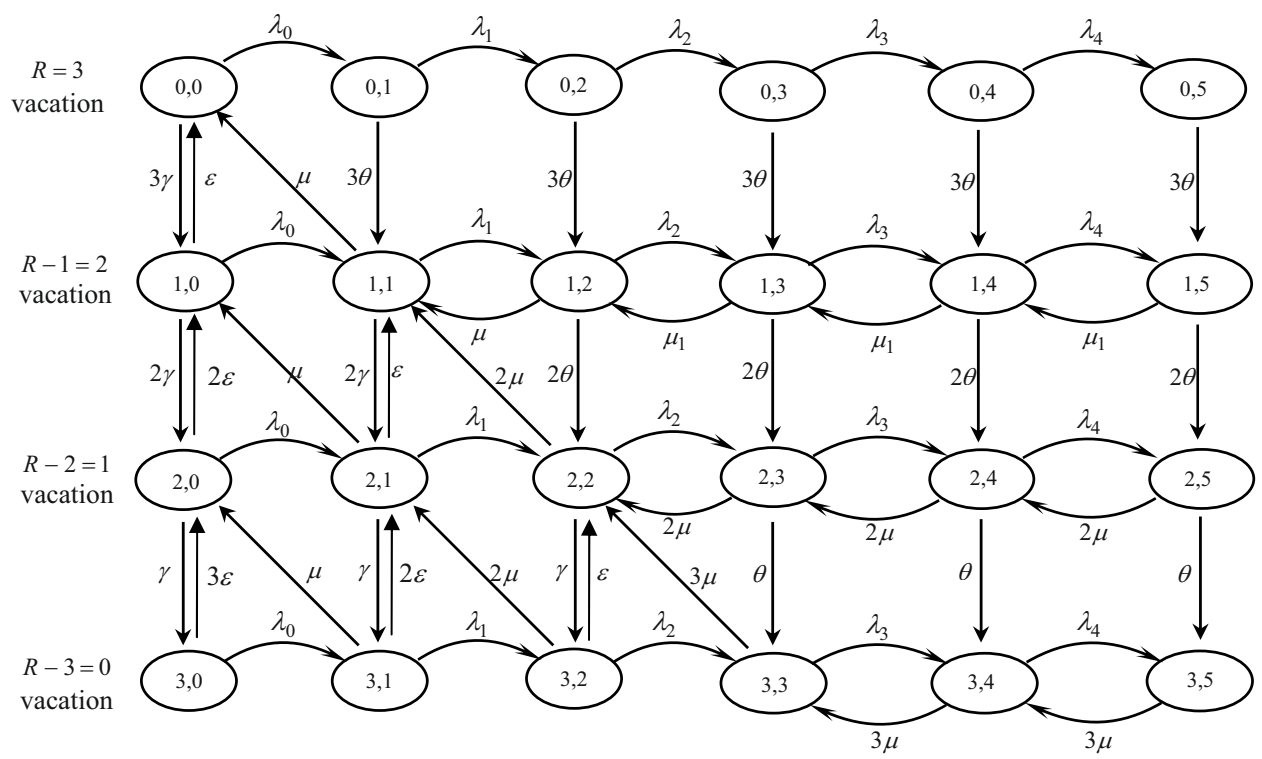

Figure 1. State-transition rate diagram for the $M / M / R$ machine-repair problem with spares and vacations (for $R=3$ and $L=5)$.

Note that the rate matrix $Q$ of this state process is similar to the quasi birth and death type, and this class of Markov process has been extensively investigated by Neuts [21]. The matrix $Q$ is a square matrix of order $(L+1)(R+1)$ and each entry of the matrix $Q$ is listed in the following:

$$
C_{i}=\left(\begin{array}{ccccccc}
u_{0, i} & 0 & 0 & \cdots & 0 & 0 & 0 \\
w_{1, i} & u_{1, i} & 0 & \cdots & 0 & 0 & 0 \\
0 & w_{2, i} & u_{2, i} & \cdots & 0 & 0 & 0 \\
0 & 0 & w_{3, i} & \cdots & 0 & 0 & 0 \\
\vdots & \vdots & \vdots & \vdots & \vdots & \vdots & \vdots \\
0 & 0 & 0 & \cdots & u_{L-2, i} & 0 & 0 \\
0 & 0 & 0 & \cdots & w_{L-1, i} & u_{L-1, i} & 0 \\
0 & 0 & 0 & \cdots & 0 & w_{L, i} & u_{L, i}
\end{array}\right), \quad 1 \leq i \leq R
$$

$$
B_{i}=\operatorname{diag}\left(b_{0, i}, b_{1, i}, \cdot, b_{L, i}\right),
$$




$$
A_{i}=\left(\begin{array}{cccccccccc}
z_{0, i} & y_{0, i} & 0 & 0 & 0 & \cdots & 0 & 0 & 0 & 0 \\
x_{1, i} & z_{1, i} & y_{1, i} & 0 & 0 & \cdots & 0 & 0 & 0 & 0 \\
0 & x_{2, i} & z_{2, i} & y_{2, i} & 0 & \cdots & 0 & 0 & 0 & 0 \\
0 & 0 & x_{3, i} & z_{3, i} & y_{3, i} & \cdots & 0 & 0 & 0 & 0 \\
\vdots & \vdots & \vdots & \vdots & \vdots & \vdots & \vdots & \vdots & \vdots & \vdots \\
0 & 0 & 0 & 0 & 0 & \vdots & z_{L-3, i} & y_{L-3, i} & 0 & 0 \\
0 & 0 & 0 & 0 & 0 & \cdots & x_{L-2, i} & z_{L-2, i} & y_{L-2, i} & 0 \\
0 & 0 & 0 & 0 & 0 & \cdots & 0 & x_{L-1, i} & z_{L-1, i} & y_{L-1, i} \\
0 & 0 & 0 & 0 & 0 & \cdots & 0 & 0 & x_{L, i} & z_{L, i}
\end{array}\right)
$$

where all $A_{i}, B_{i}$ and $C_{i}$ are square matrices of order $L+1$, and

$$
\begin{aligned}
& u_{j, i}= \begin{cases}(j-i) \epsilon, & 0 \leq j \leq i-1 \\
0, & i \leq j \leq L .\end{cases} \\
& w_{j, i}= \begin{cases}-j \mu, & 1 \leq j \leq i \\
0, & i+1 \leq j \leq L .\end{cases} \\
& b_{j, i}= \begin{cases}-(R-j) \gamma, & 0 \leq j \leq i-1 \\
-(R-j) \theta, & i \leq j \leq L .\end{cases} \\
& x_{j, i}= \begin{cases}0, & 1 \leq j \leq i \\
-i \mu, & i+1 \leq j \leq L .\end{cases} \\
& y_{j, i}= \begin{cases}-\lambda_{j}, & 0 \leq j \leq L-1 ; \\
0, & j=L .\end{cases} \\
& z_{j, i}= \begin{cases}\lambda_{j}+(R-i) \gamma+j \mu+(i-j) \epsilon, & \text { if } 0 \leq j \leq i \\
\lambda_{j}+(R-i) \theta+i \mu, & \text { if } i+1 \leq j \leq L-1 \\
(R-i) \theta+i \mu, & \text { if } j=L .\end{cases}
\end{aligned}
$$

Let $P$ denote steady-state probability vector of $Q$. By partitioning the vector $P$ as $P=\left\{P_{0}, P_{1}, P_{2}, \ldots, P_{R}\right\}$ where $P_{i}=\left\{P_{i, 0}, P_{i, 1}, P_{i, 2}, \ldots, P_{i, L}\right\}$, for $0 \leq i \leq R$ is a $1 \times(L+1)$ vector, one finds that the steady-state equations $P Q=\mathbf{0}$ are given by

$$
\begin{aligned}
P_{0} A_{0}+P_{1} C_{1} & =\mathbf{0} \\
P_{i-1} B_{i-1}+P_{i} A_{i}+P_{i+1} C_{i+1} & =\mathbf{0}, \quad 1 \leq i \leq R-1
\end{aligned}
$$

and

$$
P_{R-1} B_{R-1}+P_{R} A_{R}=\mathbf{0}
$$

After substitutions, we obtain

$$
P_{R}=-P_{R-1} B_{R-1} A_{R}^{-1},
$$




$$
\begin{gathered}
P_{i}=P_{i-1} X_{i}, \quad 1 \leq i \leq R-1 \\
P_{0}\left(A_{0}+X_{1} C_{1}\right)=\mathbf{0},
\end{gathered}
$$

where

$$
X_{i}=-B_{i-1}\left(A_{i}+X_{i+1} C_{i+1}\right)^{-1},
$$

is a $(L+1) \times(L+1)$ matrix with $C_{i}, B_{i}$ and $A_{i}$ given in (1), (2) and (3). Furthermore $X_{R}=-B_{R-1} A_{R}^{-1}$.

Equation (6) determines $P_{0}$ up to a multiplicative constant. The other equations (4) and (5) determine $P_{R}, P_{R-1}, P_{R-2}, \ldots, P_{1}$, up to the same constant, which is uniquely determined using the following normalizing equation

$$
\sum_{i=0}^{R} P_{i} \mathbf{e}=1
$$

where e represents a column vector with each component equal to one. A computer program was developed to solve $P_{i}$ and $P_{i, n}$ for $0 \leq i \leq R$, and $0 \leq n \leq L$.

\section{System performances}

Our analysis is based on the following system performance measures of the $\mathrm{M} / \mathrm{M} / \mathrm{R}$ machine repair problem with spares and server vacations. Let

$E[F] \equiv$ the expected number of failed machines in the system,

$E\left[F_{q}\right] \equiv$ the expected number of failed machines in the queue,

$E[O] \equiv$ the expected number of operating machines in the system,

$E[S] \equiv$ the expected number of spare machines in the system acting as standbys,

$E[B] \equiv$ the expected number of busy servers in the system,

$E[V] \equiv$ the expected number of vacation servers in the system,

$E[I] \equiv$ the expected number of idle servers in the system,

$M . A$. $\equiv$ machine availability (the fraction of the total time that the machines are working),

$O . U . \equiv$ operative utilization (the fraction of busy servers).

The expressions for $E[F], E\left[F_{q}\right], E[O], E[S], E[B], E[V]$ and $E[I]$ are obtained as follows:

$$
\begin{gathered}
E[F]=\sum_{i=0}^{R} \sum_{n=0}^{L} n P_{i, n}, \\
E\left[F_{q}\right]=\sum_{n=0}^{L} n P_{0, n}+\sum_{i=1}^{R} \sum_{n=0}^{i-1} n P_{i, n}+\sum_{i=1}^{R} \sum_{n=i}^{L}(n-i) P_{i, n}, \\
E[O]=M-\sum_{i=0}^{R} \sum_{n=S+1}^{L}(n-S) P_{i, n}, \\
E[S]=\sum_{i=0}^{R} \sum_{n=0}^{S}(S-n) P_{i, n},
\end{gathered}
$$




$$
\begin{gathered}
E[B]=\sum_{i=1}^{R} \sum_{n=i}^{L} i P_{i, n}, \\
E[V]=\sum_{i=0}^{R} \sum_{n=0}^{L}(R-i) P_{i, n}, \\
E[I]=R-E[B]-E[V] .
\end{gathered}
$$

Following Benson and Cox [22], the machine availability and the operative utilization are defined by

$$
\begin{gathered}
M . A .=1-\frac{E[F]}{L}, \\
\text { O.U. }=\frac{E[B]}{R} .
\end{gathered}
$$

Let $E[W]$ and $E\left[W_{q}\right]$ denote the expected waiting time in the system and the expected waiting in the queue, respectively. Using the Little's formula we obtain

$$
E[W]=E[F] / \lambda_{e}, \quad E\left[W_{q}\right]=E\left[F_{q}\right] / \lambda_{e},
$$

where the effective arrival rate into the system $\lambda_{e}=\sum_{i=0}^{R} \sum_{n=i}^{L} \lambda_{n} P_{i, n}$.

Suppose we let $\gamma=\theta$ and $\epsilon=0$, the above results can be reduced to those of machine-repair problem $\mathrm{M} / \mathrm{M} / \mathrm{R}$ models with spares and single vacation. If we take $\gamma=0$ and $\epsilon=0$, the above results can be simplified into those of machinerepair problem $\mathrm{M} / \mathrm{M} / \mathrm{R}$ models with spares and multiple vacations. If $\gamma=\theta$ and $\epsilon \neq 0$, the above results can be reduced to those of machine-repair problem $\mathrm{M} / \mathrm{M} / \mathrm{R}$ model with spares and hybrid single/multiple vacation.

\section{Cost analysis For the Vacation models}

We construct a total expected cost function per unit time for the $M / M / R$ machine repair problem with spares and server vacations under three vacation policies, and impose a constraint on the system availability in which $S$ and $R$ are decision variables. Our objective is to determine the optimum number of spares $S$, say $S^{*}$, and the optimum number of servers $R$, say $R^{*}$, simultaneously so that the cost is minimized and the system availability is maintained at a certain level. First let

$C_{h} \equiv$ cost per unit time when one failed machine joins the system,

$C_{e} \equiv$ cost per unit time of a failed machine after all spares are exhausted (downtime cost),

$C_{s} \equiv$ cost per unit time when one machine is functioning as a spare (inventory cost),

$C_{b} \equiv$ cost per unit time when one server is busy,

$C_{i} \equiv$ cost per unit time when one server is idle,

$C_{f} \equiv$ cost per unit time of each server,

$r \equiv$ reward per unit time when one server is on vacation. 
We assume the total expected cost function to be linear with respect to the indicated quantities. Accordingly,

$T_{\text {cost }}(S, R)=C_{h} E[F]+C_{e}(M-E[O])+C_{s} E[S]+C_{b} E[B]+C_{i} E[I]+R C_{f}-r E[V]$.

The production system always requires minimum of $M$ machines in operation. The cost minimization problem can be illustrated mathematically as:

$$
\underset{S, R}{\operatorname{Minimize}} T_{\text {cost }}(S, R) \text {. }
$$

Subject to:

$$
A . V .=\sum_{i=0}^{R} \sum_{n=0}^{S} P_{i, n} \geq A,
$$

where $A . V$. is the steady-state probability that at least $M$ machines are in operation and function properly (system availability), and $A$ is the minimum fraction of time all $M$ machines are in operation and function properly.

The decision variables $S$ and $R$ are required to be integer values and to be determined by (18) and (19). However, it is extremely difficult to develop analytical results for the optimum values $S^{*}$ and $R^{*}$ because the expected cost function $T_{\text {cost }}(S, R)$ is highly non-linear and complex. We will perform some numerical experiments to show that the minimum expected cost function indeed exists and therefore the optimum solution $\left(S^{*}, R^{*}\right)$ is obtained, which minimizes the cost function under the availability constraint (19).

\section{Sensitivity AnALysis}

We perform a sensitivity analysis for changes in the joint optimum values $S^{*}$ and $R^{*}$ along with changes in specific values of the system parameters $\lambda, \alpha, \mu$ and $\theta$. A numerical illustration is provided by considering $M=10$ and the following cost parameters:

$$
\begin{gathered}
A=0.8, \quad C_{h}=\$ 10 / \text { day, } \quad C_{e}=\$ 100 / \text { day, } \quad C_{s}=\$ 50 / \text { day } \\
C_{b}=\$ 55 / \text { day, } C_{i}=\$ 40 / \text { day, } \quad C_{f}=\$ 75 / \text { day, } \quad r=\$ 60 / \text { day }
\end{gathered}
$$

The upper bounds used on the decision variables $S$ and $R$ are $2 M$. For the machine repair problem M/M/R model with Policy 3 the expected cost $T_{\text {cost }}(S, R)$ is shown in Figure 2 for different values of $(S, R)$. We note that a minimum expected cost per day of $\$ 518.539$ is achieved at $S^{*}=3$ and $R^{*}=5$. It should be to note that the optimum solution $\left(S^{*}, R^{*}\right)$ is unique while the constraint (19) is satisfied (i.e. A.V. $\geq 0.8)$.

The minimum expected cost $T_{\text {cost }}(S, R)$ and the values of various system performance measures A.V., $E[F], E\left[F_{q}\right], E[O], E[S], E[V], E[I], M . A$., and $O . U$. at the optimum values $S^{*}$ and $R^{*}$ are shown in Tables 1-6 for different policies and different values of $(\lambda, \alpha)$ and $(\theta, \mu)$. 


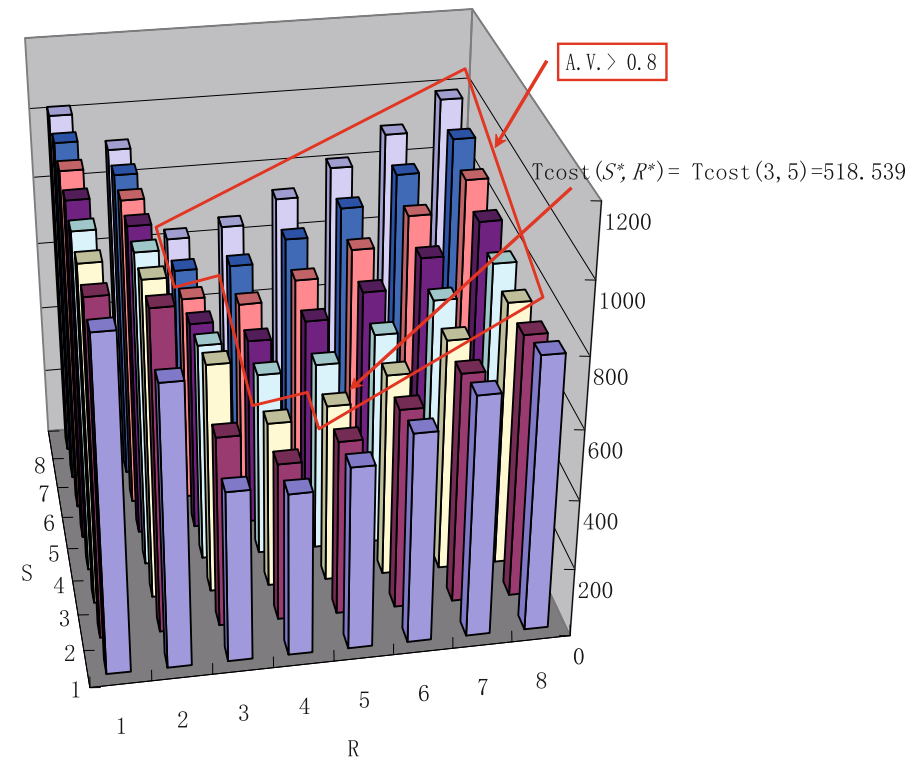

Figure 2. The expected cost Tcost $(S, R)$ for the machine-repair problem with spares and vacations $(\varepsilon=1.0, \gamma=\theta=5.0, \lambda=$ $1.2, \alpha=0.01, \mu=5)$.

From Tables 1-6, one sees that (i) $T_{\text {cost }}\left(S^{*}, R^{*}\right)$ increases as $\lambda$ or $\alpha$ increases; (ii) the optimum values of $S$ and $R, S^{*}$ and $R^{*}$ increase as $\lambda$ increases. From the last three columns of Tables 1,3 and $5, S^{*}$ and $R^{*}$ are not affected at all when $\alpha$ varies from 0.05 to 0.1 for all policies. But $S^{*}$ increases as $\alpha$ increases and $R^{*}$ decreases as $\alpha$ increases for Policies 2-3. One also observes (i) $T_{\text {cost }}\left(S^{*}, R^{*}\right)$ increases as $\mu$ decreases; (ii) $S^{*}$ and $R^{*}$ decrease as $\theta$ or $\mu$ increases.

As shown in Tables 1-6, it appears that for three policies (i) parameter $\alpha$ rarely affects $S^{*}$ when $\alpha$ gets smaller; and (ii) parameters $\lambda, \theta$ and $\mu$ affect the optimal values $S^{*}$ and $R^{*}$ significantly.

The expected cost $T_{\text {cost }}(S, R)$ of the various values $S$ and $R$ is shown in Figures 3-6 for three different policies and various values of $(\lambda, \alpha, \theta, \mu)$. We find from Figures 3-6 that Policy 2 is better than Policy 3, which in turn is better than Policy 1. As the availability reaches 0.8 under other parameters being given, it can be seen that (i) the expected cost increases as $S$ increases; and (ii) the expected cost increases as $R$ increases for smaller $\theta$.

\section{Conclusions}

This paper we developed the analytical steady-state results for the M/M/R machine repair problem with spares and server vacations. The results are easily computed using a computer program. We show that the results are more general 
TABLE 1. System performance measures of the machine-repair problem with spares and single vacation under optimal operating conditions $(\varepsilon=0, \gamma=\theta=1.0, \mu=5)$.

\begin{tabular}{ccccccc}
\hline \multicolumn{7}{c}{ (Policy 1) } \\
\hline$(\lambda, \alpha)$ & $(1.2,0.05)$ & $(1.0,0.05)$ & $(0.8,0.05)$ & $(0.6,0.05)$ & $(0.6,0.1)$ & $(0.6,0.6)$ \\
\hline$(S *, R *)$ & $(\mathbf{5}, \mathbf{8})$ & $(\mathbf{5 , 6})$ & $(\mathbf{4}, \mathbf{6})$ & $(\mathbf{4}, \mathbf{4})$ & $(\mathbf{4}, \mathbf{4})$ & $(\mathbf{4 , 4})$ \\
Tcost $(S *, R *)$ & $\mathbf{5 8 3 . 1 1 7 6}$ & $\mathbf{5 0 5 . 9 6 7 6}$ & $\mathbf{4 5 3 . 2 2 9 2}$ & $\mathbf{3 7 4 . 7 7 5 3}$ & $\mathbf{3 7 4 . 7 9 2 1}$ & $\mathbf{3 7 7 . 8 7 2 1}$ \\
A.V. & 0.8183 & 0.8239 & 0.8487 & 0.8502 & 0.8459 & 0.8097 \\
$E[F]$ & 3.5050 & 3.3792 & 2.5167 & 2.4205 & 2.4676 & 2.8473 \\
$E\left[F_{q}\right]$ & 1.5152 & 1.6230 & 1.2104 & 1.3441 & 1.3703 & 1.5805 \\
$E[O]$ & 9.6271 & 9.6240 & 9.7069 & 9.6754 & 9.6662 & 9.5901 \\
$E[S]$ & 1.8678 & 1.9967 & 1.7764 & 1.9041 & 1.8662 & 1.5625 \\
$E[B]$ & 1.9898 & 1.7562 & 1.3063 & 1.0764 & 1.0972 & 1.2668 \\
$E[V]$ & 5.3246 & 3.8160 & 3.9966 & 2.5324 & 2.5303 & 2.4872 \\
$E[I]$ & 0.6856 & 0.4277 & 0.6970 & 0.3912 & 0.3725 & 0.2460 \\
M.A. & 0.7663 & 0.7747 & 0.8202 & 0.8271 & 0.8237 & 0.7966 \\
O.U. & 0.2487 & 0.2927 & 0.2177 & 0.2691 & 0.2743 & 0.3167 \\
\hline
\end{tabular}

TABLE 2. System performance measures of the machine-repair problem with spares and single vacation under optimal operating conditions $(\varepsilon=0, \gamma=\theta, \lambda=1.0, \alpha=0.02)$.

\begin{tabular}{ccccccc}
\hline \multicolumn{7}{c}{ (Policy 1) } \\
\hline$(\theta, \mu)$ & $(0.5,4.0)$ & $(1.0,4.0)$ & $(10,4.0)$ & $(5.0,2.0)$ & $(5.0,4.0)$ & $(5.0,10)$ \\
\hline$(S *, R *)$ & $(\mathbf{6 , 9})$ & $(\mathbf{5}, \mathbf{7})$ & $(\mathbf{4}, \mathbf{5})$ & $(\mathbf{7 , 9})$ & $(\mathbf{4 , 6})$ & $(\mathbf{2}, \mathbf{3})$ \\
$\mathrm{T} \operatorname{cost}(S *, R *)$ & $\mathbf{6 2 1 . 2 2 8 8}$ & $\mathbf{5 7 5 . 9 0 2 7}$ & $\mathbf{6 9 5 . 8 9 6 8}$ & $\mathbf{1 0 9 8 . 0 4 3 8}$ & $\mathbf{6 7 0 . 6 0 2 2}$ & $\mathbf{3 2 7 . 2 2 1 7}$ \\
$\mathrm{A} . \mathrm{V}$. & 0.8034 & 0.8051 & 0.8159 & 0.8448 & 0.8679 & 0.8147 \\
$E[F]$ & 4.2778 & 3.6051 & 3.1829 & 5.2329 & 2.6414 & 1.4687 \\
$E\left[F_{q}\right]$ & 2.0628 & 1.5210 & 1.8713 & 3.4306 & 1.6208 & 0.7096 \\
$E[O]$ & 9.5466 & 9.5964 & 9.3010 & 9.5924 & 9.7516 & 9.6134 \\
$E[S]$ & 2.1756 & 1.7985 & 1.5161 & 2.1746 & 1.6070 & 0.9179 \\
$E[B]$ & 2.2150 & 2.0841 & 1.3116 & 1.8023 & 1.0206 & 0.7592 \\
$E[V]$ & 6.4389 & 4.2670 & 0.7631 & 1.6581 & 1.6631 & 1.2841 \\
$E[I]$ & 0.3461 & 0.6489 & 2.9253 & 5.5396 & 3.3163 & 0.9567 \\
M.A. & 0.7326 & 0.7597 & 0.7727 & 0.6922 & 0.8113 & 0.8776 \\
O.U. & 0.2461 & 0.2977 & 0.2623 & 0.2003 & 0.1701 & 0.2531 \\
\hline
\end{tabular}

than existing results in the literature (see Sivazlian and Wang [3], Gupta [15], and Gross and Harris [20]). For the vacation model, a total expected cost function subjected to a minimum specified level of system availability is developed to determine the optimal number of spares and the number of servers simultaneously, so as to minimize the total expected cost function. From the numerical investigations, we show that Policy 2 is superior to Policy 1 or Policy 3. It is to be noted that the 
TABLE 3. System performance measures of the machine-repair problem with spares and multiple vacations under optimal operating conditions $(\varepsilon=0, \gamma=0, \theta=1.0, \mu=5)$.

\begin{tabular}{ccccccc}
\hline \multicolumn{7}{c}{ (Policy 2) } \\
\hline$(\lambda, \alpha)$ & $(1.2,0.05)$ & $(1.0,0.05)$ & $(0.8,0.05)$ & $(0.6,0.05)$ & $(0.6,0.1)$ & $(0.6,0.6)$ \\
\hline$(S *, R *)$ & $(\mathbf{6}, \mathbf{7})$ & $(\mathbf{5}, \mathbf{7})$ & $(\mathbf{4}, \mathbf{7})$ & $(\mathbf{3}, \mathbf{7})$ & $(\mathbf{3 , 7})$ & $(\mathbf{4 , 5})$ \\
Tcost $(S *, R *)$ & $\mathbf{5 6 3 . 1 2 0 5}$ & $\mathbf{4 9 4 . 3 3 0 6}$ & $\mathbf{4 2 4 . 5 8 8 6}$ & $\mathbf{3 5 3 . 5 2 5 0}$ & $\mathbf{3 5 4 . 6 5 3 3}$ & $\mathbf{3 6 7 . 1 9 2 9}$ \\
A.V. & 0.8085 & 0.8130 & 0.8165 & 0.8198 & 0.8175 & 0.8232 \\
$E[F]$ & 4.3090 & 3.5505 & 2.8123 & 2.0908 & 2.1104 & 2.8196 \\
$E\left[F_{q}\right]$ & 1.9882 & 1.6095 & 1.2532 & 0.9162 & 0.9244 & 1.4769 \\
$E[O]$ & 9.5761 & 9.6124 & 9.6481 & 9.6861 & 9.6821 & 9.6629 \\
$E[S]$ & 2.1149 & 1.8371 & 1.5396 & 1.2231 & 1.2074 & 1.5175 \\
$E[B]$ & 2.3208 & 1.9410 & 1.5591 & 1.1746 & 1.1860 & 1.3428 \\
$E[V]$ & 4.6792 & 5.0590 & 5.4409 & 5.8254 & 5.8140 & 3.6572 \\
$E[I]$ & 0.0000 & 0.0000 & 0.0000 & 0.0000 & 0.0000 & 0.0000 \\
M.A. & 0.7307 & 0.7633 & 0.7991 & 0.8392 & 0.8377 & 0.7986 \\
O.U. & 0.3315 & 0.2773 & 0.2227 & 0.1678 & 0.1694 & 0.2686 \\
\hline
\end{tabular}

TABLE 4. System performance measures of the machine-repair problem with spares and multiple vacations under optimal operating conditions $(\varepsilon=0, \gamma=0, \lambda=1.0, \alpha=0.02)$.

\begin{tabular}{ccccccc}
\hline \multicolumn{7}{c}{ (Policy 2) } \\
\hline$(\theta, \mu)$ & $(0.5,4.0)$ & $(1.0,4.0)$ & $(10,4.0)$ & $(5.0,2.0)$ & $(5.0,4.0)$ & $(5.0,10)$ \\
\hline$(S *, R *)$ & $(\mathbf{8}, \mathbf{7})$ & $(\mathbf{6}, \mathbf{7})$ & $(\mathbf{4 , 6})$ & $(\mathbf{7 , 9})$ & $(\mathbf{4 , 6})$ & $(\mathbf{2 , 5})$ \\
Tcost $(S *, R *)$ & $\mathbf{6 3 1 . 2 5 6 6}$ & $\mathbf{5 7 1 . 2 4 6 5}$ & $\mathbf{5 0 6 . 6 8 0 8}$ & $\mathbf{9 0 4 . 5 0 7 4}$ & $\mathbf{5 0 6 . 0 3 1 9}$ & $\mathbf{2 7 1 . 0 7 4 2}$ \\
A.V. & 0.8165 & 0.8298 & 0.8455 & 0.8066 & 0.8087 & 0.8171 \\
$E[F]$ & 5.5030 & 4.1655 & 2.8126 & 5.5502 & 3.0107 & 1.4307 \\
$E\left[F_{q}\right]$ & 3.1041 & 1.7419 & 0.3383 & 0.6132 & 0.5623 & 0.4563 \\
$E[O]$ & 9.5300 & 9.6390 & 9.7024 & 9.5083 & 9.6340 & 9.7250 \\
$E[S]$ & 2.9671 & 2.1956 & 1.4850 & 1.9415 & 1.3552 & 0.8443 \\
$E[B]$ & 2.3989 & 2.4236 & 2.4743 & 4.9370 & 2.4484 & 0.9743 \\
$E[V]$ & 4.6011 & 4.5764 & 3.5257 & 4.0630 & 3.5516 & 4.0257 \\
$E[I]$ & 0.0000 & 0.0000 & 0.0000 & 0.0000 & 0.0000 & 0.0000 \\
M.A. & 0.6943 & 0.7397 & 0.7991 & 0.6735 & 0.7849 & 0.8808 \\
O.U. & 0.3427 & 0.3462 & 0.4124 & 0.5486 & 0.4081 & 0.1949 \\
\hline
\end{tabular}

conclusion is only valid for the parameter settings considered in this paper. We may reach other conclusion for other parameter settings examined. Incorporating the optimal scheduling of repairmen vacation into a complex machine-repair problem is worthy of further investigation. 
TABLE 5. System performance measures of the machine-repair problem with spares and hybrid/single vacation under optimal operating conditions $(\varepsilon=1.0, \gamma=\theta=1.0, \mu=5)$.

\begin{tabular}{ccccccc}
\hline \multicolumn{7}{c}{ (Policy 3) } \\
\hline$(\lambda, \alpha)$ & $(1.2,0.05)$ & $(1.0,0.05)$ & $(0.8,0.05)$ & $(0.6,0.05)$ & $(0.6,0.1)$ & $(0.6,0.6)$ \\
\hline$(S *, R *)$ & $(\mathbf{5}, \mathbf{8})$ & $(\mathbf{5}, \mathbf{6})$ & $(\mathbf{4}, \mathbf{6})$ & $(\mathbf{3}, \mathbf{5})$ & $(\mathbf{3 , 5})$ & $(\mathbf{4 , 4})$ \\
$\mathrm{T} \operatorname{cost}(S *, R *)$ & $\mathbf{5 7 6 . 8 1 5 7}$ & $\mathbf{5 0 1 . 5 6 0 8}$ & $\mathbf{4 4 3 . 1 6 8 3}$ & $\mathbf{3 6 4 . 2 4 0 9}$ & $\mathbf{3 6 4 . 3 9 4 9}$ & $\mathbf{3 7 4 . 9 0 6 7}$ \\
$\mathrm{A} . \mathrm{V}$. & 0.8113 & 0.8176 & 0.8386 & 0.8195 & 0.8161 & 0.8037 \\
$E[F]$ & 3.5600 & 3.4334 & 2.5916 & 2.0234 & 2.0496 & 2.8916 \\
$E\left[F_{q}\right]$ & 1.5289 & 1.6534 & 1.2399 & 1.0267 & 1.0394 & 1.6156 \\
$E[O]$ & 9.6106 & 9.6088 & 9.6847 & 9.6610 & 9.6548 & 9.5761 \\
$E[S]$ & 1.8293 & 1.9578 & 1.7237 & 1.3156 & 1.2956 & 1.5323 \\
$E[B]$ & 2.0311 & 1.7800 & 1.3517 & 0.9967 & 1.0102 & 1.2759 \\
$E[V]$ & 5.3965 & 3.8649 & 4.1074 & 3.4562 & 3.4556 & 2.5215 \\
$E[I]$ & 0.5723 & 0.3552 & 0.5409 & 0.5471 & 0.5342 & 0.2026 \\
M.A. & 0.7627 & 0.7711 & 0.8149 & 0.8444 & 0.8423 & 0.7935 \\
O.U. & 0.2539 & 0.2967 & 0.2253 & 0.1993 & 0.2020 & 0.3190 \\
\hline
\end{tabular}

TABLE 6. System performance measures of the machine-repair problem with spares and hybrid/single vacation under optimal operating conditions $(\varepsilon=1.0, \gamma=\theta, \lambda=1.0, \alpha=0.02)$.

\begin{tabular}{ccccccc}
\hline \multicolumn{7}{c}{$($ Policy 3) } \\
\hline$(\theta, \mu)$ & $(0.5,4.0)$ & $(1.0,4.0)$ & $(10,4.0)$ & $(5.0,2.0)$ & $(5.0,4.0)$ & $(5.0,10)$ \\
\hline$(S *, R *)$ & $(\mathbf{7 , 8})$ & $(\mathbf{6 , 6})$ & $(\mathbf{4}, \mathbf{5})$ & $(\mathbf{7 , 9})$ & $(\mathbf{4 , 6})$ & $(\mathbf{2 , 3})$ \\
$\mathrm{T} \operatorname{cost}(S *, R *)$ & $\mathbf{6 2 8 . 2 0 2 3}$ & $\mathbf{5 8 1 . 4 7 3 9}$ & $\mathbf{6 8 2 . 9 6 4 0}$ & $\mathbf{1 0 6 4 . 0 2 6 7}$ & $\mathbf{6 4 4 . 8 5 4 9}$ & $\mathbf{3 1 9 . 8 4 0 4}$ \\
$\mathrm{A} . \mathrm{V}$. & 0.8247 & 0.8197 & 0.8141 & 0.8425 & 0.8639 & 0.8071 \\
$E[F]$ & 4.7378 & 4.1699 & 3.1918 & 5.2466 & 2.6621 & 1.5011 \\
$E\left[F_{q}\right]$ & 2.4416 & 1.8979 & 1.8206 & 3.2505 & 1.5248 & 0.7157 \\
$E[O]$ & 9.5786 & 9.5695 & 9.2975 & 9.5887 & 9.7438 & 9.5974 \\
$E[S]$ & 2.6835 & 2.2606 & 1.5107 & 2.1647 & 1.5941 & 0.9015 \\
$E[B]$ & 2.2963 & 2.2721 & 1.3712 & 1.9961 & 1.1373 & 0.7854 \\
$E[V]$ & 5.4994 & 3.4038 & 0.9031 & 2.0275 & 1.9415 & 1.3729 \\
$E[I]$ & 0.2044 & 0.3241 & 2.7257 & 4.9764 & 2.9212 & 0.8417 \\
M.A. & 0.7213 & 0.7394 & 0.7720 & 0.6914 & 0.8099 & 0.8749 \\
O.U. & 0.2870 & 0.3787 & 0.2742 & 0.2218 & 0.1895 & 0.2618 \\
\hline
\end{tabular}

Acknowledgements. The authors are indebted to Editor-in-chief, Professor Alain BILLIONNET, and Associate Editor, whose constructive comments have led to a substantial improvement in the presentation of the paper. This work was partly supported by the National Science Council of Taiwan, Republic of China, under grant number NSC 94-2213-E-025-002. 


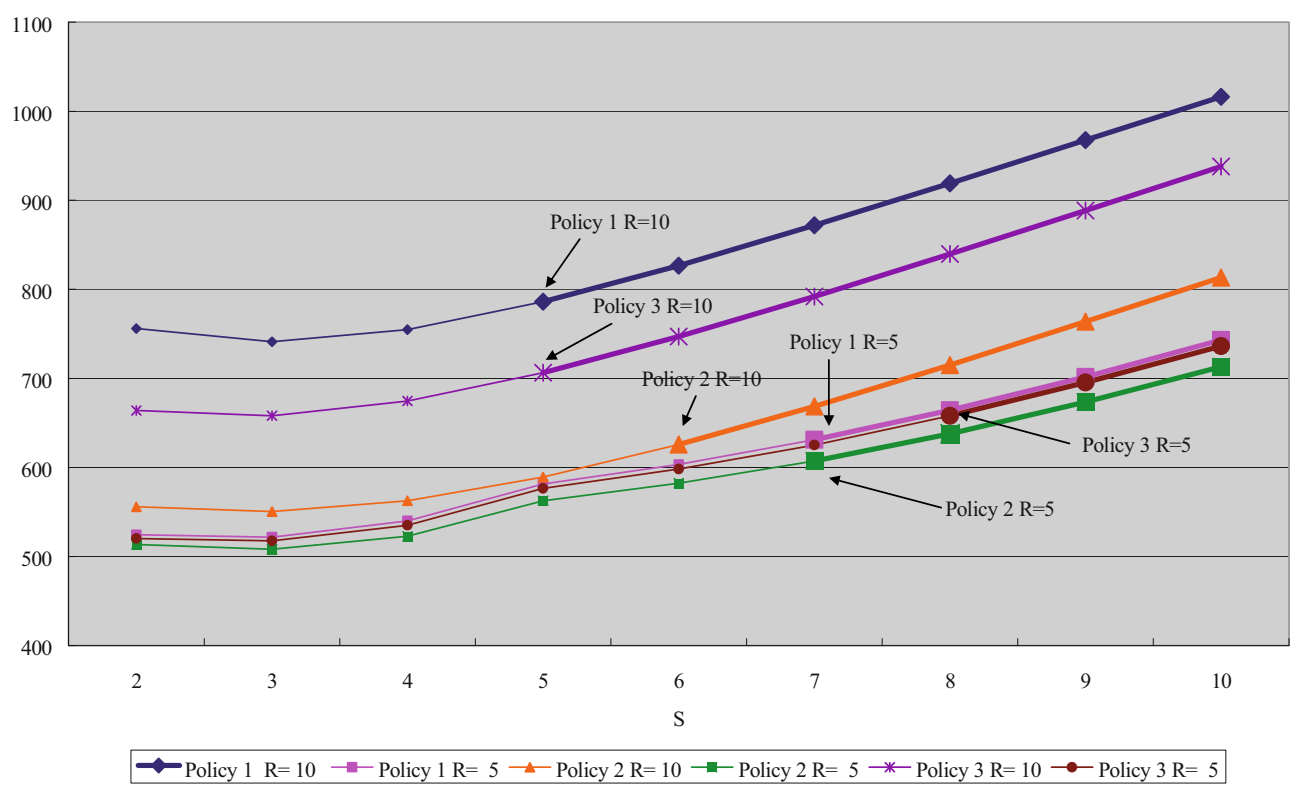

* The broad line indicates that A.V. reaches 0.8. For example, in Policy 1 $R=10$, the A.V. is greater than 0.8 since $S=4$. ${ }^{* *}$ We set $\varepsilon=1.0$ for Policy 3 .

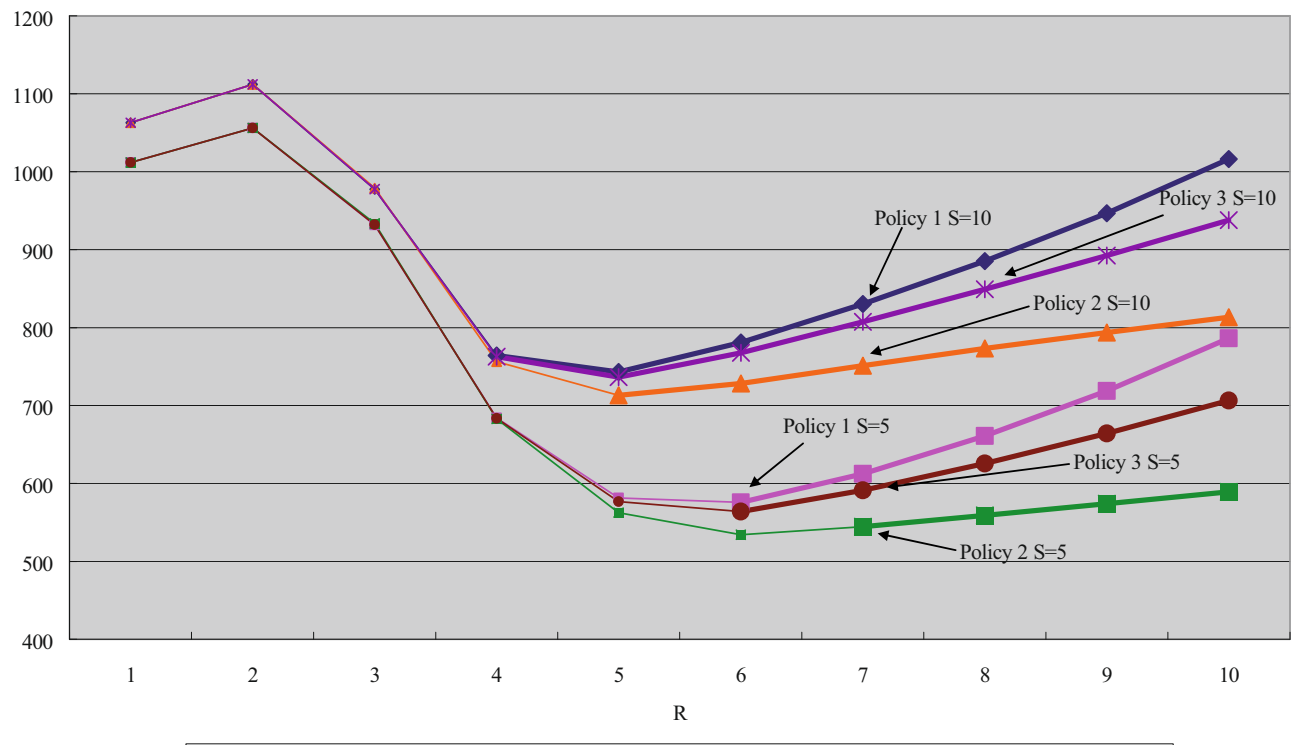

$\rightarrow$ Policy $1 \mathrm{~S}=10 \rightarrow$ Policy $1 \mathrm{~S}=5 \rightarrow$ Policy $2 \mathrm{~S}=10 \rightarrow$ Policy $2 \mathrm{~S}=5 \rightarrow$ Policy $3 \mathrm{~S}=10 \rightarrow$ Policy $3 \mathrm{~S}=5$

Figure 3. The expected cost Tcost $(S, R)$ for three different policies based on various values of $S$ and $R(\theta=1.0, \lambda=0.8, \alpha=$ $0.02, \mu=2.5)$. 


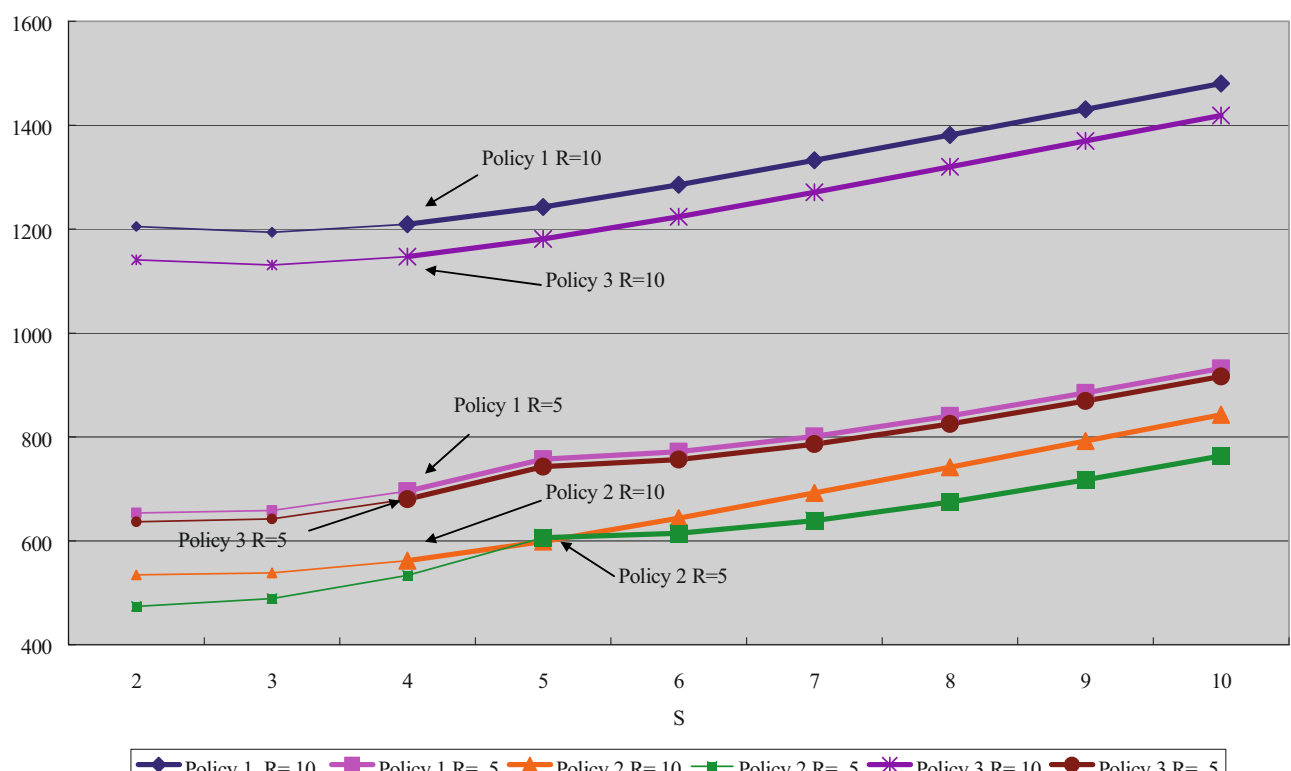

-Policy $1 \mathrm{R}=10 \multimap$ Policy $1 \mathrm{R}=5 \rightarrow$ Policy $2 \mathrm{R}=10 \rightarrow$ Policy $2 \mathrm{R}=5 \rightarrow$ Policy $3 \mathrm{R}=10 \multimap$ Policy $3 \mathrm{R}=5$

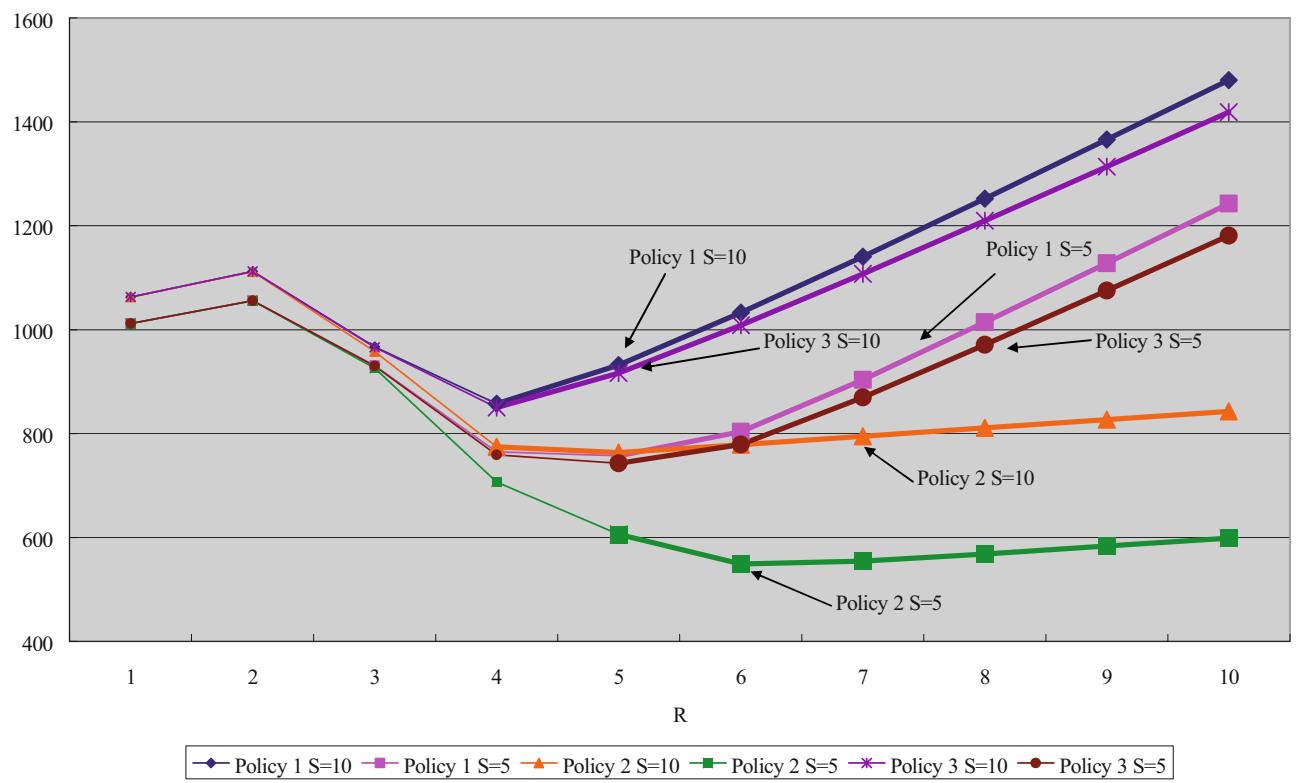

Figure 4 . The expected cost $\mathrm{T} \operatorname{cost}(S, R)$ for three different policies based on various values of $S$ and $R(\theta=10.0, \lambda=0.8, \alpha=$ $0.02, \mu=2.5)$. 


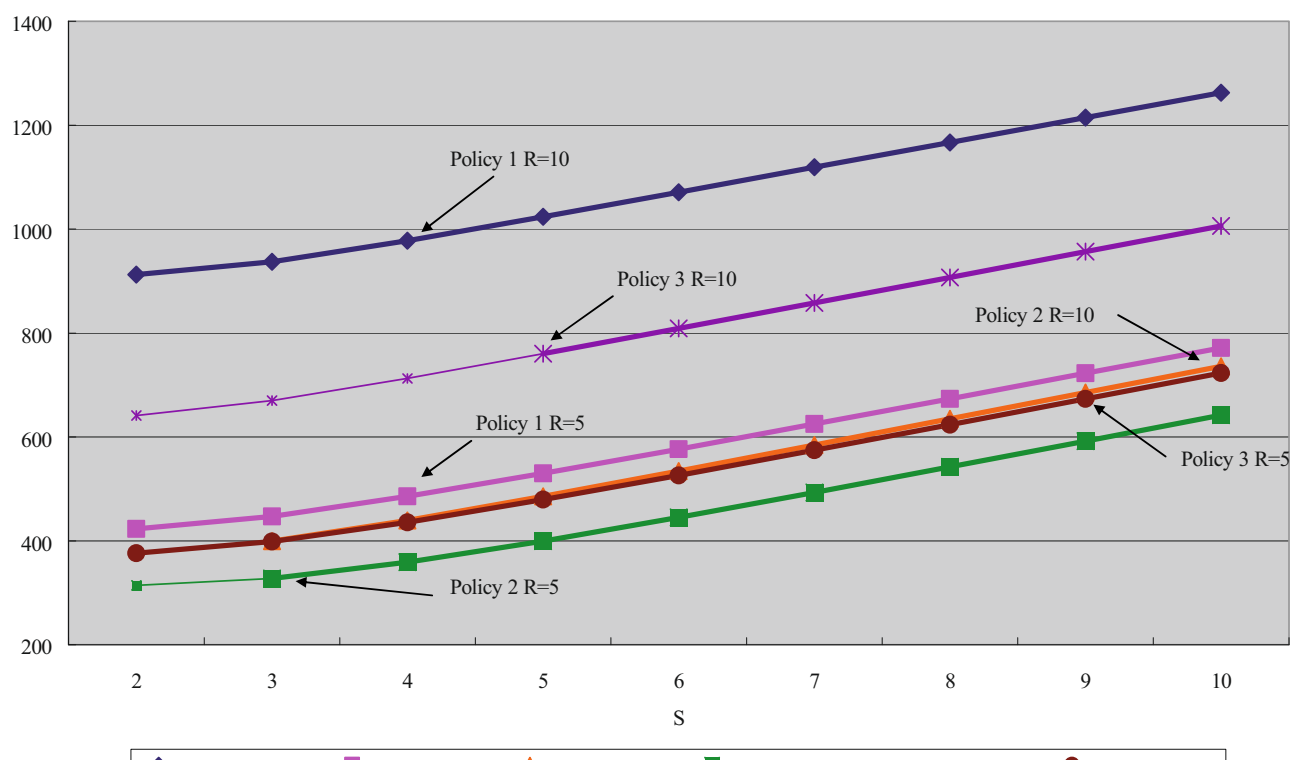

$\multimap$ Policy $1 \mathrm{R}=10 \leadsto$ - Policy $1 \mathrm{R}=5 \multimap$ Policy $2 \mathrm{R}=10 \leadsto$ Policy $2 \mathrm{R}=5 \rightarrow$ - Policy $3 \mathrm{R}=10 \leadsto$ Policy $3 \mathrm{R}=5$

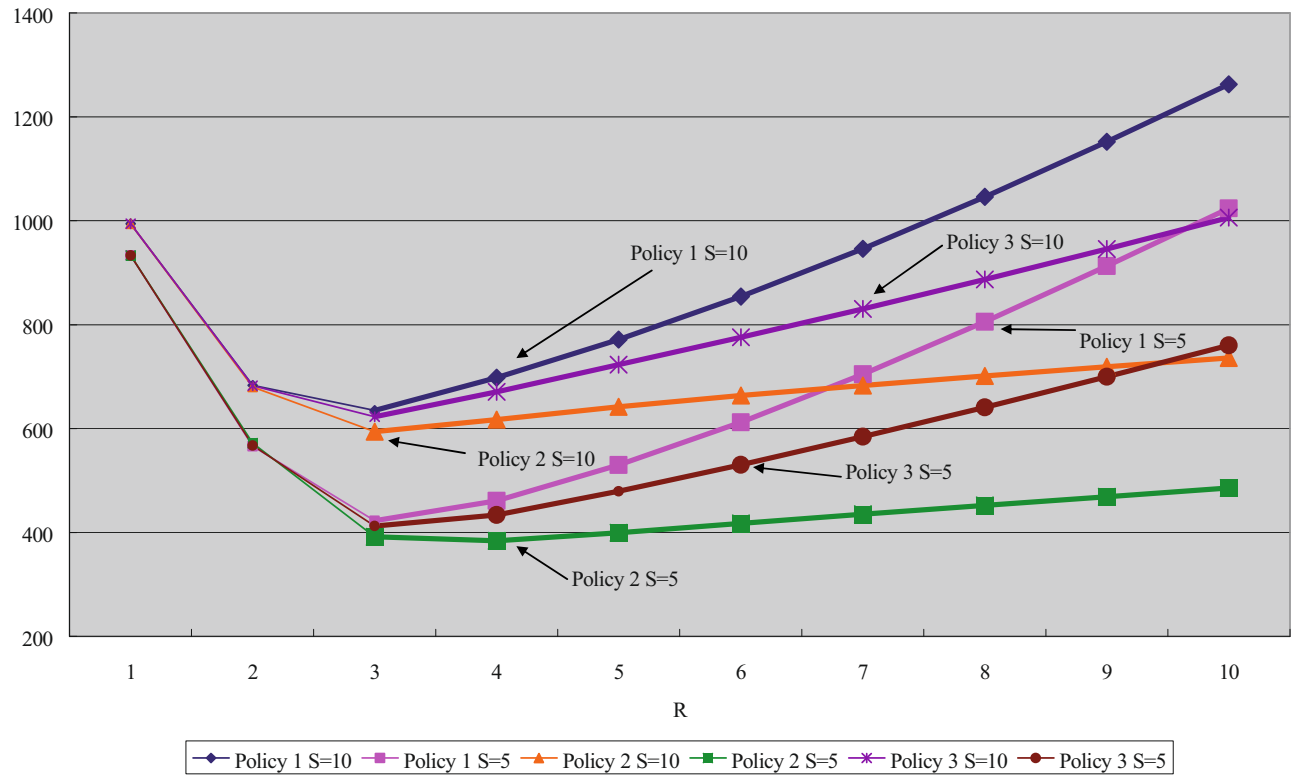

Figure 5. The expected cost Tcost $(S, R)$ for three different policies based on various values of $S$ and $R(\theta=1.0, \lambda=0.4, \alpha=$ $0.02, \mu=2.5)$. 


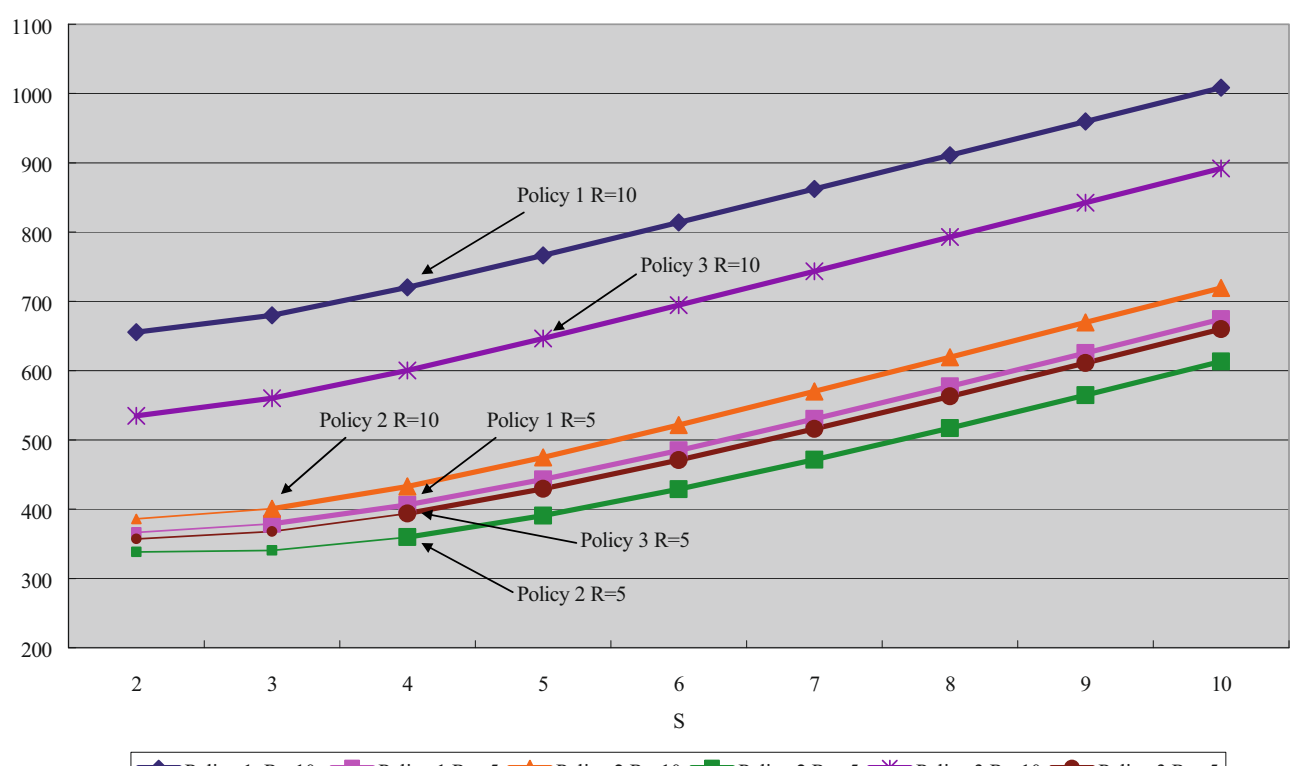

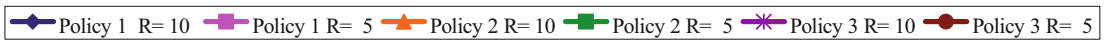

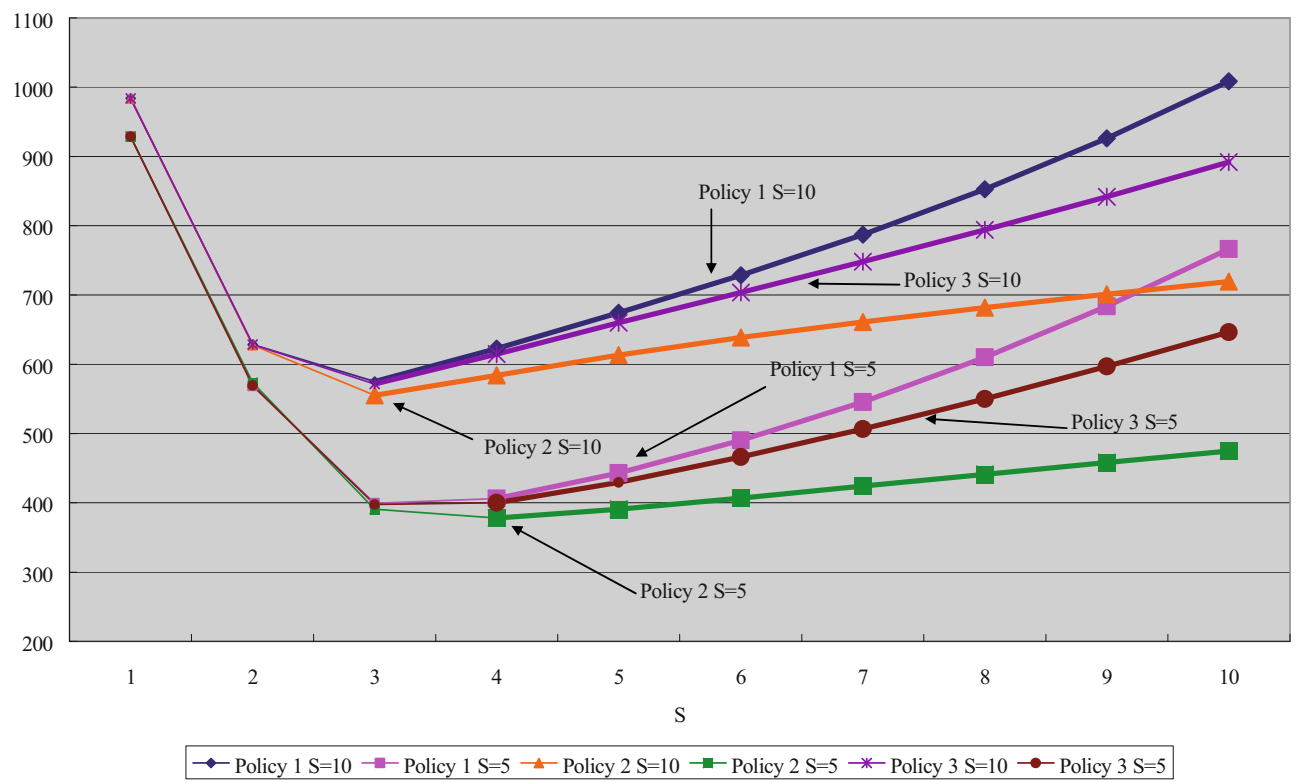

Figure 6 . The expected cost Tcost $(S, R)$ for three different policies based on various values of $S$ and $R(\theta=1.0, \lambda=0.8, \alpha=$ $0.02, \mu=5.0)$. 


\section{REFERENCES}

[1] W. Feller, An introduction to probability theory and its applications, Vol. I. John Wiley and Sons, New York (1967).

[2] F.J. Toft and H. Boothroyd, A queueing model for spare coal faces. Oper. Res. Quart. 10 (1959) 245-251.

[3] B.D. Sivazlian and K.-H. Wang, Economic analysis of the $M / M / R$ machine repair problem with warm standbys. Microelectron. Reliab. 29 (1989) 25-35.

[4] K.-H. Wang, Cost analysis of the $M / M / R$ machine repair problem with mixed standby spares. Microelectron. Reliab. 33 (1993) 1293-1301.

[5] K.-H. Wang and H.-C. Lee, Cost analysis of the cold-standby M/M/R machine repair problem with multiple modes of failure. Microelectron. Reliab. 38. (1998) 435-441.

[6] M. Jain, Rakhee and S. Maheshwari, N-policy for a machine repair system with spares and reneging. Appl. Math. Model. 28 (2004) 513-531.

[7] H. Ashcroft, The productivity of several machines under the care of one operator. J. $R$. Stat. Soc. B 12 (1950) 145-151.

[8] E.A. Elsayed, An optimum repair policy for the machine interference problem. J. Oper. Res. Soc. 32 (1981) 793-801.

[9] J.E. Hilliard, An approach to cost analysis of maintenance float systems. IIE Trans. 8 (1976) $128-133$.

[10] D. Gross, H.D. Kahn and J.D. Marsh, Queueing models for spares provisioning. Nav. Res. Logist. Quart. 24 (1977) 521-536.

[11] D. Gross, D.R. Miller and R.M. Soland, A closed queueing network model for multi-echelon repairable item provisioning. IIE Trans. 15 (1983) 344-352.

[12] K.H. Wang, J.B. Ke and J.C. Ke, Profit analysis of the M/M/R machine repair problem with balking, reneging, and standby switching failures. Comput. Oper. Res. 34 (2007) 835-847.

[13] B.T. Doshi, Queueing system with vacations-a survey. Queueing Syst. 1 (1986) 29-66.

[14] H. Takagi, Queueing analysis: A foundation of performance evaluation, Vol. I. Vacation and priority systems, Part I. North-Holland, Amsterdam (1991).

[15] S.M. Gupta, Machine interference problem with warm spares, server vacations and exhaustive service. Perform. Eval. 29 (1997) 195-211.

[16] M. Jain, Rakhee and M. Singh, Bilevel control of degraded machining system with warm standbys, setup and vacation. Appl. Math. Model 28 (2004) 1015-1026.

[17] J.C. Ke, Vacation policies for machine interference problem with an un-reliable server and state-dependent service rate. J. Chinese Institute Industrial Engineers 23 (2006) 100-114.

[18] O.C. Ibe and K.S. Trivedi, Stochastic Petri net analysis of finite population vacation queueing systems. Queueing Syst. 8 (1991) 111-128.

[19] K. Chelst, A.Z. Tilles and J.S. Pipis, A coal unloader: a finite queueing system with breakdowns. Interfaces 11 (1981) 12-24.

[20] D. Gross and C.M. Harris, Fundamentals of queueing theory. 3rd ed., John Wiley and Sons, New York (1998).

[21] M.F. Neuts, Matrix geometric solutions in stochastic models: an algorithmic approach. The Johns Hopkins University Press, Baltimore (1981)

[22] F. Benson and D.R. Cox, The productivity of machines requiring attention at random interval. J. R. Stat. Soc. B 13 (1951) 65-82. 